\title{
O Brutesco na Matriz de Santo Antônio de Tiradentes
}

\author{
Luiz Antonio da Cruz ${ }^{1}$ \\ DOI: 10.20396/eha.v0i14.3544
}

O Arraial de Santo Antônio foi instalado por volta de 1702, em 1710 fora fundada a Irmandade do Santíssimo Sacramento, sendo uma de suas primeiras iniciativas a substituição da capela primitiva por um templo mais adequado, amplo e ricamente decorado. A localidade logo passou a ser conhecida como Arraial Velho do Rio das Mortes, após a instalação do Arraial de Nossa Senhora do Pilar-o Arraial Novo, que veio ser a atual São João del-Rei. A robusta produção de ouro propiciou ao arraial edificar um templo grande e magnífico, com o que melhor havia de materiais, mão de obra e estilo.

Infelizmente, toda documentação da primeira fase da edificação se perdeu, com o desaparecimento do primeiro Livro de Receita e Despesa da Irmandade do Santíssimo Sacramento (1710-1736) - da construtora do templo. É certo que na primeira metade do setecentos a capela-mor e a nave da Matriz de Santo Antônio ${ }^{2}$ estavam praticamente prontas, com talha joanina primorosamente executada pela oficina do entalhador português ]oão Ferreira Sampaio ${ }^{3}$, com a participação de outros entalhadores, como Pedro Monteiro de Souza.

Sobre a decoração do interior dessa matriz, Germain Bazin registrou:

A capela-mor de Tiradentes foi executada entre 1739-1741 pelo entalhador João Ferreira Sampayo. Ela é um dos mais admiráveis conjuntos de talha do Brasil. Em nenhum outro lugar, exceto, talvez na capela-mor de Tibães, em Portugal, a talha atingiu tamanha força de expressão espacial como nas formidáveis reviravoltas de volutas douradas [...]. ${ }^{4}$

Mais recentemente, o pesquisador português Eduardo Pires deOliveira, especialista em talha, registrou em sua obra Minho e Minas Cerais no Século XVIII:

[...] depois de alguns bons retábulos do período nacional, sobreveio um conjunto de obras joaninas, que puderam conviver, como na matriz de Tiradentes, e a exemplo do que aconteceu conosco.

No período joanino iremos já encontrar excelentes retábulos, executados de modo exímio um pouco por todo lado. E o cume é atingido na igreja matriz de Tiradentes, cuja capela-mor tem uma

\footnotetext{
${ }^{1}$ UFMG - EAU / NPGAU

${ }^{2}$ Tombamento Federal Individual pelo IPHAN, registrado como Matriz de Santo Antônio (Tiradentes, MG). Denominação: Igreja Matriz de Santo Antônio. Processo: 405-T-49. Livro: Belas Artes Vol. 1, Nº de Inscrição: 329, Nº da folha: 69, Data: 29 de novembro de 1949.

${ }^{3}$ João Ferreira Sampaio era natural de São Paio, Parada de Tibães, que fora uma freguesia do Concelho de Braga. Ainda não se localizou referência sobre o ano em que migrou para o Brasil.

${ }^{4}$ BAZIN, Germain. A arquitetura religiosa Barroca no Brasil - Estudo histórico e morfológico. Rio de Janeiro: Editora Record, s.d., p. 348.
} 
talha tão túrgida, tão imponente, tão voluptuosa, tão sensorial que mais parece uma obra que se integra perfeitamente na natureza tropical quando ela está pujante, após o período das grandes chuvas $[\ldots]^{5}$

Conforme observado por estes dois pesquisadores, a decoração joanina de Matriz de Santo Antônio é realmente exuberante. Trata-se de talha densa, profunda e elegante. Especialmente a capela-mor que é toda revestida por elementos artísticos e em suas ilhargas destacam-se duas pinturas a óleo de grandes proporções, com amplas molduras douradas e ovais, de autoria de João Batista da Rosa, executadas entre 1738-39, apresentam as cenas da Última Ceia e a Bodas de Caná6 (Fig.01). A talha "gorda" desenvolveu-se compondo variados elementos como os aplicados no arco-cruzeiro, nas ilhargas, nas colunas e no trono - valendo-se de muitos elementos como colunas retas, formas conchóides, volutas, acantos, cartelas, docéis com lambrequins e pingentes, palmetas, guirlandas, anjos, atlantes, marmanjos, planejamentos, mascarões, entablamentos, balaustrada e figuras alegóricas: da Fé à direita e da Fortaleza à esquerda.

O camarim tem trono composto por agigantadas conchas e robustas volutas, tudo encimado por uma cabeça de serafim, que abriga a imagem do padroeiro. Ao fundo, onde está o orago, encontra-se um círculo em aureola, preenchido com cabecinhas angelicais e muitos frisos com entalhes variados. No período da Semana Santa o camarim do altar-mor era fechado por uma tela com o motivo O Jumento se Curva Diante da Eucaristia ${ }^{7}$, essa obra ficara bastante danifica, após intervenção de restauro, encontra-se exposta na nave ${ }^{8}$, em frente ao órgão. Essas três pinturas são de autoria de João Batista da Rosa e executadas na década de 1730. A decoração da nave e do coro receberam também talha joanina, que se salientam ainda mais pelo contraste com os muros brancos. (fig 2)

Nos ambientes profusamente decorados, destacam-se os tetos pintados, o da capela-mor, o da nave, do nártex e do coro. A que tudo indica, esse conjunto de tetos foi pintado por um dos integrantes da oficina de João Ferreira Sampaio, o português e mestre pintor António Caldas, conforme registro de Judith Martins, em seu Dicionário de Artistase Artífices dos Séculos XVIII XIX em Minas Gerais:

1751/1752 - Recebeu 7:200\$000 "por que se ajustou a dita obra" de pintura e douramento da igreja, na forma do termo a fls. 37 ( $L^{\circ} 2^{\circ}$ de "Receita e Despesa" da Irmandade do SS. Sacramento, fls. 105) ${ }^{9}$

\footnotetext{
${ }^{5}$ OLIVEIRA, Eduardo Pires de. Minho e Minas Gerais no século XVIII. Braga: Edição do autor, p. 98.

${ }^{6}$ A pintura Bodas de Caná apareceu no ensaio de Hannah Levy, Modelos europeus na pintura colonial, publicado na Revista do SPHAN, Rio de Janeiro: 1944, vol. 8, p. 62-3, obra inspirada na estampa do livro Vita, Passio, Morset Resurrectio]esu Christi, editado por Adriano Collart e Joan Galle, em Antuérpia, sem data.

${ }^{7}$ O Jumento se Curva Diante da Eucaristica - Durante uma pregação sobre a eucaristia, um homem levantou-se dizendo: "Acreditarei que Cristo está realmente presente na Hóstia Consagrada, quando vir o meu jumento ajoelhar-se diante da custódia com o Santíssimo. Sacramento". O santo aceitou o desafio. Deixaram o animal três dias sem comer e beber. No momento e lugar préestabelecidos, apresentou-se Antônio com a custódia ao herege e seu jumento. Mesmo faminto, o animal deixou de lado o alimento e a água que lhe ofereceram, para se ajoelhar diante ao Santíssimo Sacramento.

${ }^{8}$ Das telas que fechavam baca de camarim de altar-mor, durante a Semana Santa, peças de grandes dimensões, subsistem raras, uma delas encontra-se na Matriz de Santo Antônio, em Santa Bárbara, obra da oficina do Mestre Manoel da Costa Ataíde (17621830), no momento em precária conservação.

${ }^{9}$ MARTINS, Judith. Dicionário de Artistas e Artífices dos Séculos XVIII e XIX em Minas Gerais. Rio de Janeiro: Publicações do Instituto do Patrimônio Histórico e Artístico Nacional, N²7, 1974, p. 142, primeiro volume.
} 
Em período anterior, em 1745, António Caldas encontrava-se trabalhando no douramento de retábulo da Matriz de Santo Antônio, em Ouro Branco ${ }^{10}$ e a que tudo indica, juntamente com a oficina de João Ferreira Sampaio (fig. 3 e 4).

Tanto na talha, no douramento e nas pinturas, prevalece uma homogeneidade na qualidade, no domínio das técnicas e soluções plásticas. Porém, chama-nos a atenção a solução para o modelo de forro e o tipo de pintura. A solução para o teto da capela-mor é em abóbada de aresta"1 quadripartida, com pouca volumetria e ao centro, dividindo as faces da abóbada, um florão dourado ladeado por folhas de acanto. A pintura é em ouro, com sombreado em tom marrom escuro, que salienta os volumes. O fundo, originalmente branco, propiciava maior contraste entre os tons. Após a intervenção de restauração realizada a partir do início da década de 1960, pelo restaurador Edson Mota e sua equipe do Rio de Janeiro ${ }^{12}$. A leitura visual deste teto ficou bastante comprometida pelo uso da cera de abelha para preenchimento das aberturas causadas pelos insetos xilófagos e para fixar a camada pictórica. Essa intervenção comprometeu acentuadamente o fundo branco que contrastava com os demais tons. Com a presença da cera, o teto ficou em tom pastel.

A composição dessa pintura apresenta ampla gramática pictórica do Proto-Barroco e uma face pintada foi espelhada nas demais. Na base, ao centro, há um semiarco elevado, tendo um vaso maior centralizado enas laterais vasos menores, ladeados por cariátides com os seios expostos. Há uma profusão de elementos fitomórficos que se desenvolvem em rolos, três guirlandas de flores a cada lado - que saem da boca de pequenas carraras de perfil, conectam-se ao vaso central que está encimado por uma concha, de onde saem desenhos simétricos para fechar a composição com uma concha bem mais volumosa. Ainda na parte interna da capela-mor, na estrutura que compõe o arco-cruzeiro, sobre fundo claro, foi aplicada uma pintura com elementos brutescados, em tom vermelho. Uma faixa pintada exatamente ao lado da coluna mais trabalhada, tão exageradamente entalhada, que parece perder sua função de sustentação arquitetônica. (fig. 5 e 6)

O teto da nave é em abóbada de aresta, apainelado, trifacetado, composto por dezoito caixotões. Cada um apresenta uma cena litúrgica do Antigo Testamento, centralizada e envolta por ampla cartela de brutesco, pintada a ouro, tom marrom para dara volumetria e com o fundo originalmente em branco. As cenas receberam um friso

\footnotetext{
${ }^{10}$ PEDROSA, Aziz José de Oliveira. A produção da talha joanina na Capitania de Minas Gerais - retábulos, entalhadores e oficinas. Belo Horizonte: Incipit, 2019, p. 238.

${ }^{11}$ CRUZ, Luiz Antonio da. e BOAVENTURA, Maria José. Glossário do Patrimônio de Tiradentes-MG. Tiradentes: IHGT, 2015, p. 27.

${ }^{12}$ Arquivo Central do IPHAN - RJ. Na equipe de Edson Mota estavam os seguintes ajudantes do Rio de Janeiro: Mário Rodrigues, José Morais e Oldak de Freitas. Os ajudantes locais foram Antônio Correia, Antônio Comes de Matos, José Celso Matias, Manuel Trindade do Pilar, Guido Caetano e Otávio Fonseca. Participou ainda Geraldo Francisco Xavier, de Congonhas.
} 


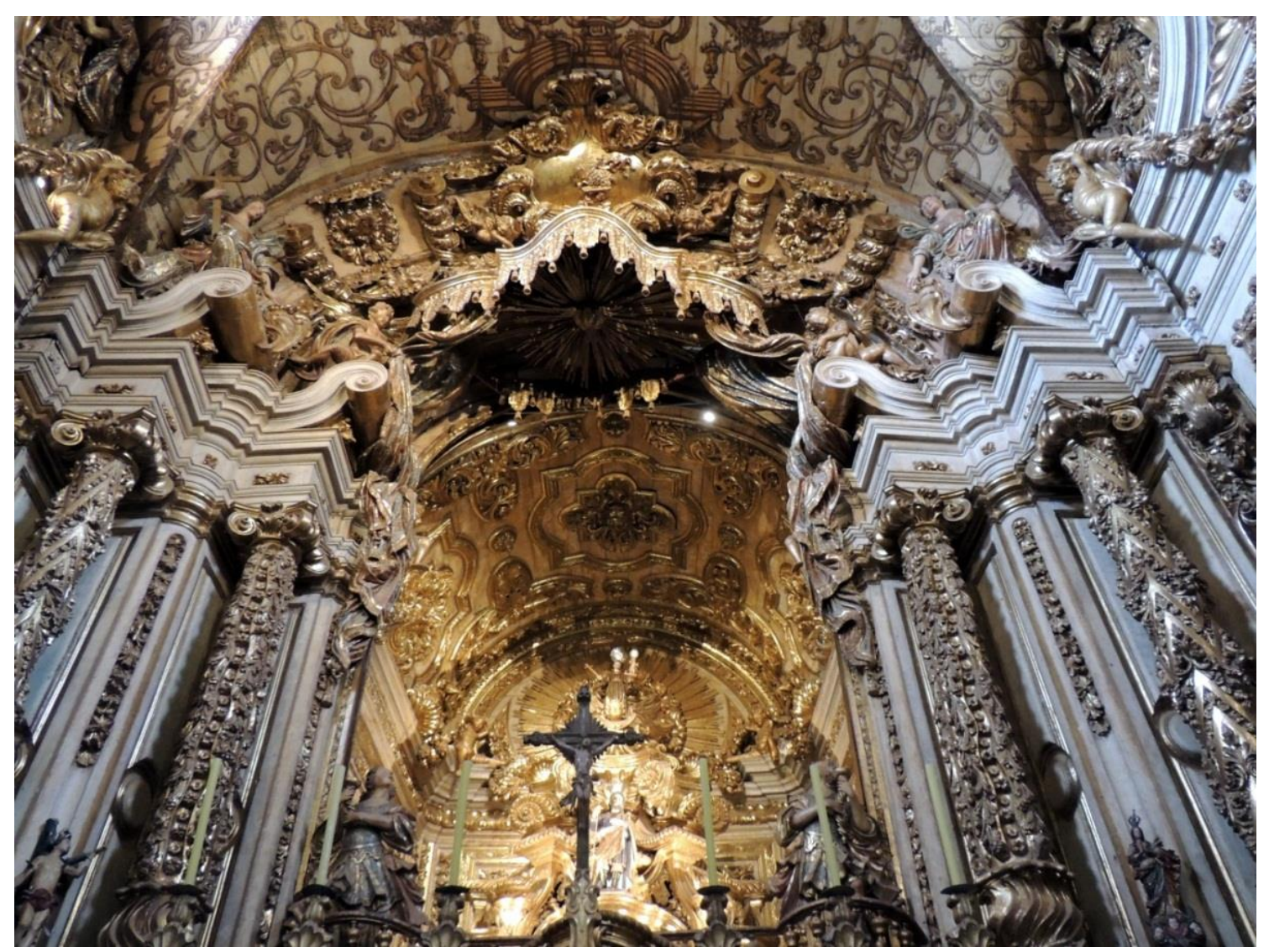

[Figura 1] Aspecto da capela-mor da Matriz de Santo Antônio. Fotografia do autor, 2019.

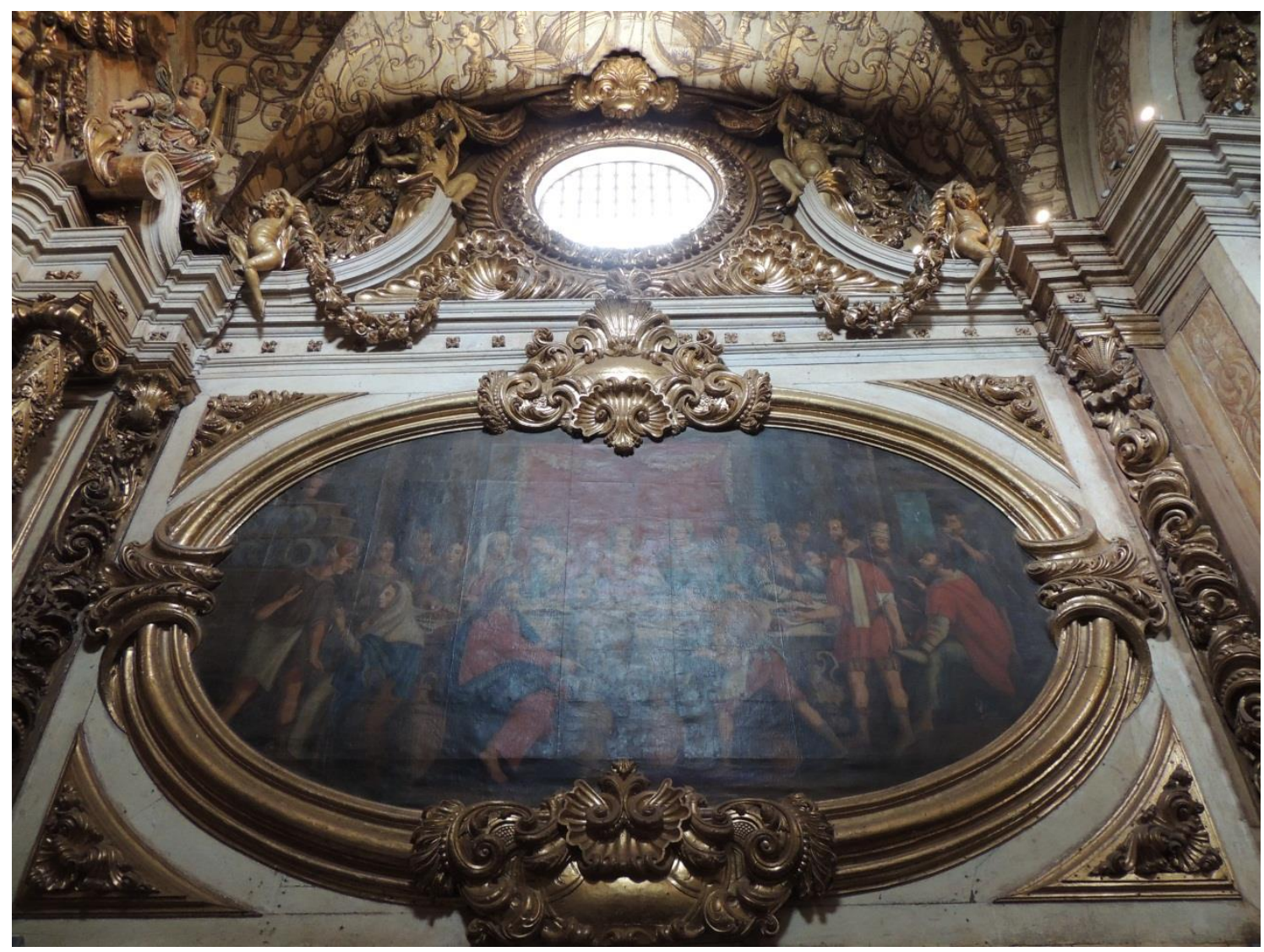

[Figura 02] As Bodas de Caná, de pintura de João Batista da Rosa, capela-mor da Matriz de Santo Antônio. Foto do autor, 2019. 


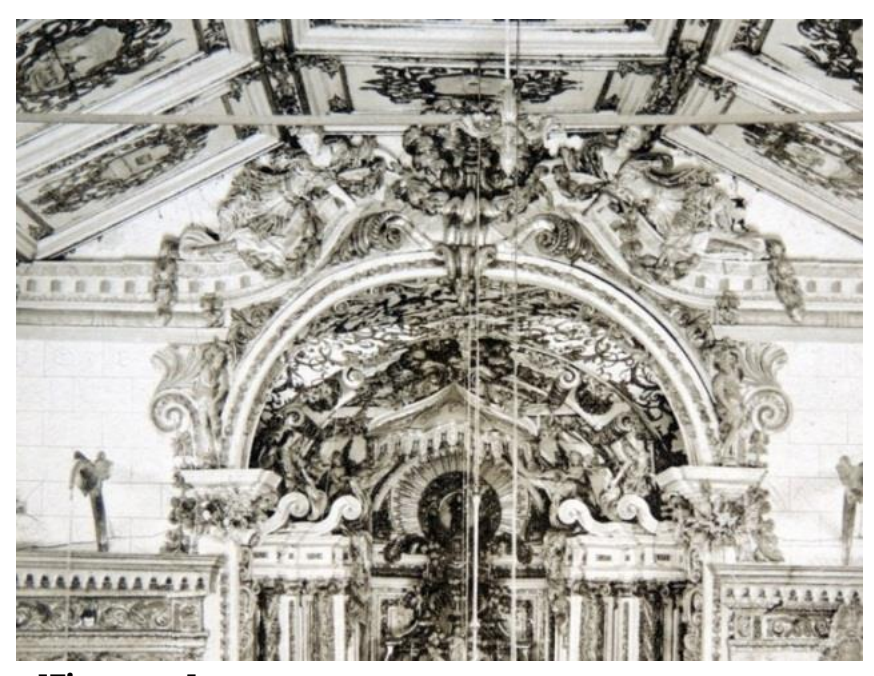

[Figura 03]

Matriz de Santo Antônio, antes da intervenção de restauração, detalhe.Década de 1940, Relíquias da Terra do Ouro. Acervo do autor.

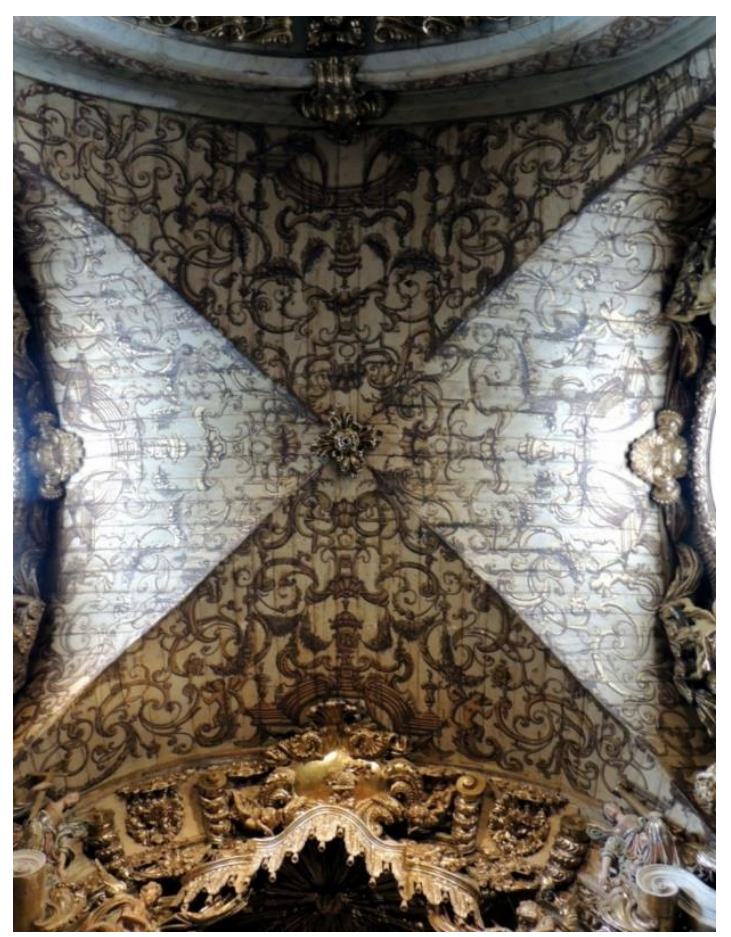

[Figura 05] Ferronerie - teto da capela-mor. Matriz de Santo Antônio. Autoria: António Caldas, século XVIII. Fotografia do autor, 2018.

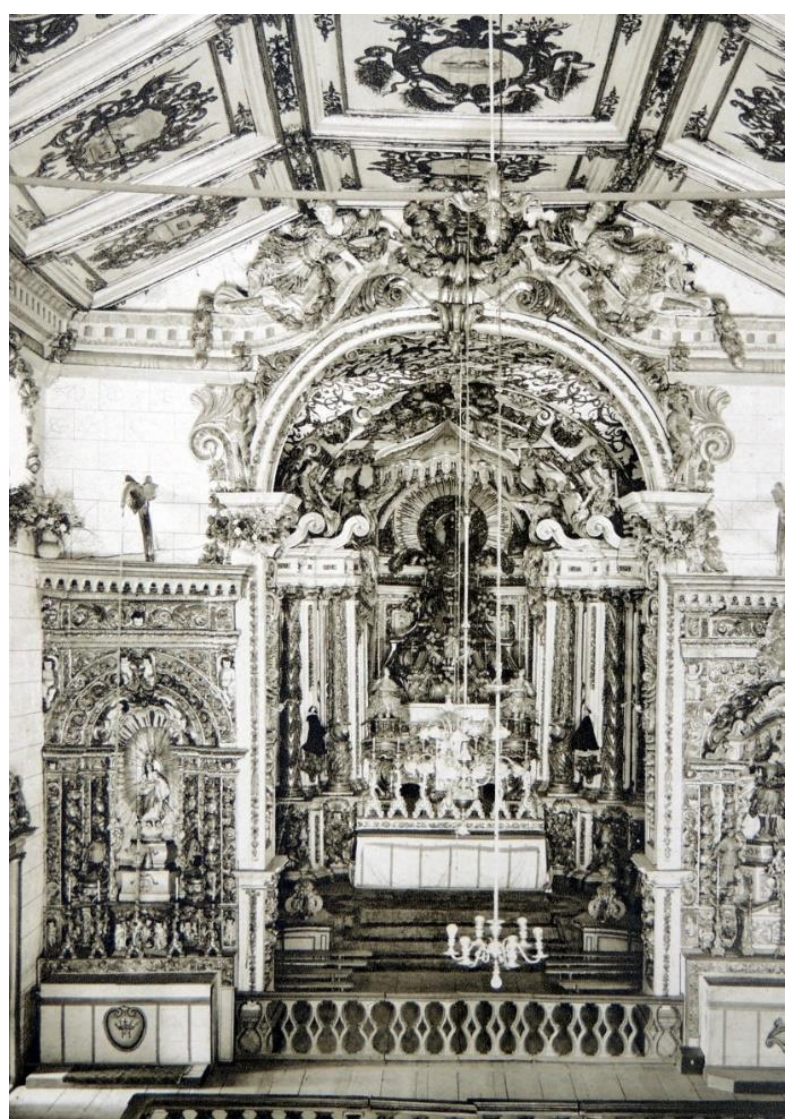

[Figura 04]

Matriz de Santo Antônio, antes da intervenção de restauro. Década de 1940, Relíquias da Terra do Ouro, de Edgard de Cerqueira Falcão. Acervo do autor.

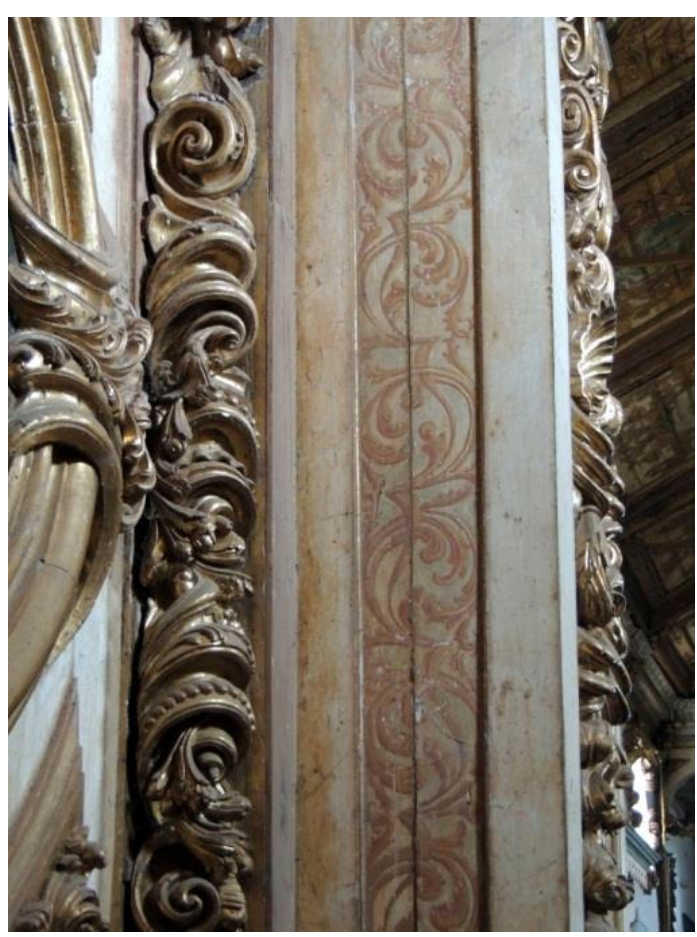

[Figura 06] Detalhe da capela-mor da Matriz de Santo Antônio, com coluna entalhada e brutesco pintado. Foto do autor, 2019. 
saliente dourado, com pinturas nos cantos, são separadas por molduras mais amplas e entre cada uma destaca-se um florão dourado. Os motivos das cartelas são aos pares ${ }^{13}$, repetindo os motivos nas laterais, os centrais são diferentes, todos com variadas soluções fitomórficas, antropormóficas e zoomóricas - volumosas guirlandas de flores, conchas, cariátides com os seios expostos, guillochés, carraras, cachos de uvas, aves e ramos de trigo. A leitura visual do teto da nave também foi comprometida pelo uso da cera de abelha para afixar a camada pictórica e preencher as áreas atacadas pelos insetos xilófagos. Como o teto da capela-mor, o da nave está em estreito diálogo com os demais elementos decorativos entalhados, especialmente os retábulos. Na nave, com a presença do branco dos muros, há mais contrates tanto com o teto pintado quanto com a talha joanina. (fig. 7, 8 e 9)

O coro tem o teto pintado com formas fitomórficas, em tons vermelho, verde e amarelo, em determinados pontos detalhes em ouro. Teto dividido em três módulos, geminados, que repetem a mesma composição pictórica. Nessa complexa trama brutescada, com muitas ramas, folhas e botões de flores, destacam-se a cada lado um parde cornucópias com flores e uma fita verde. Ao centro, o florão dourado e a cada lado guillochés preenchidos por pontos. A movimentada, colorida e exuberante solução pictórica desse teto complementa a decoração escultórica, com as guirlandas douradas que pendem dos arcos abatidos, das colunas em estípite. Infelizmente, a leitura visual desse teto ficou acentuadamente prejudicada após a restauração executada pelo IPHAN, na década de 1960. A cera de abelha comprometeu para sempre o fundo branco da pintura, que ficou em tom rebaixado. Além disso, recentemente sofre com as intempéries, especialmente com as águas pluviais e o ataque de insetos xilófagos. (fig 10e 11)

O teto do nártex apresenta um brutesco colorido, com as formas fitomórficas em tons verde, vermelho e ocre que se desenvolvem sobre o fundo branco. Ao centro de cada lado, foi repetido o semiarco, exatamente como no teto da capela-mor, porém, mais simplificado e envolvido por conchas. As formas se desenvolvem até o centro, que tem um florão dourado, solução idêntica ao teto da capela-mor e ao da nave. Felizmente, esse teto foi o único que não passou por obra de restauro e com sua preservação, podemos imaginar o acentuado contraste que os demais tiveram. A solução pictórica desse teto, mais simplificada e com elementos fitomórficos, nos lembra mais o arabesco. (fig.12)

Ainda, no altar lateral, o do Descendimento da Cruz, nos nichos, onde se encontram as imagens de São Joaquim e de Santana, o fundo foi decorado com pintura brutescada, em ouro e tom marrom, com a mesma solução do teto da capela-mor. No altar de Nossa Senhora da Piedade, o camarim recebeu pintura de brutesco, em fundo vermelho, no teto - com diferente qualidade e solução, ao fundo o mesmo motivo é entalhado. No camarim do altar de Nossa Senhora do Rosário, a decoração também é brutescada, porém

\footnotetext{
${ }^{13} \mathrm{Na}$ obra de restauro executada pelo IPHAN, na década de 1960, um dos caixotões foi montado fora da sequência.
} 

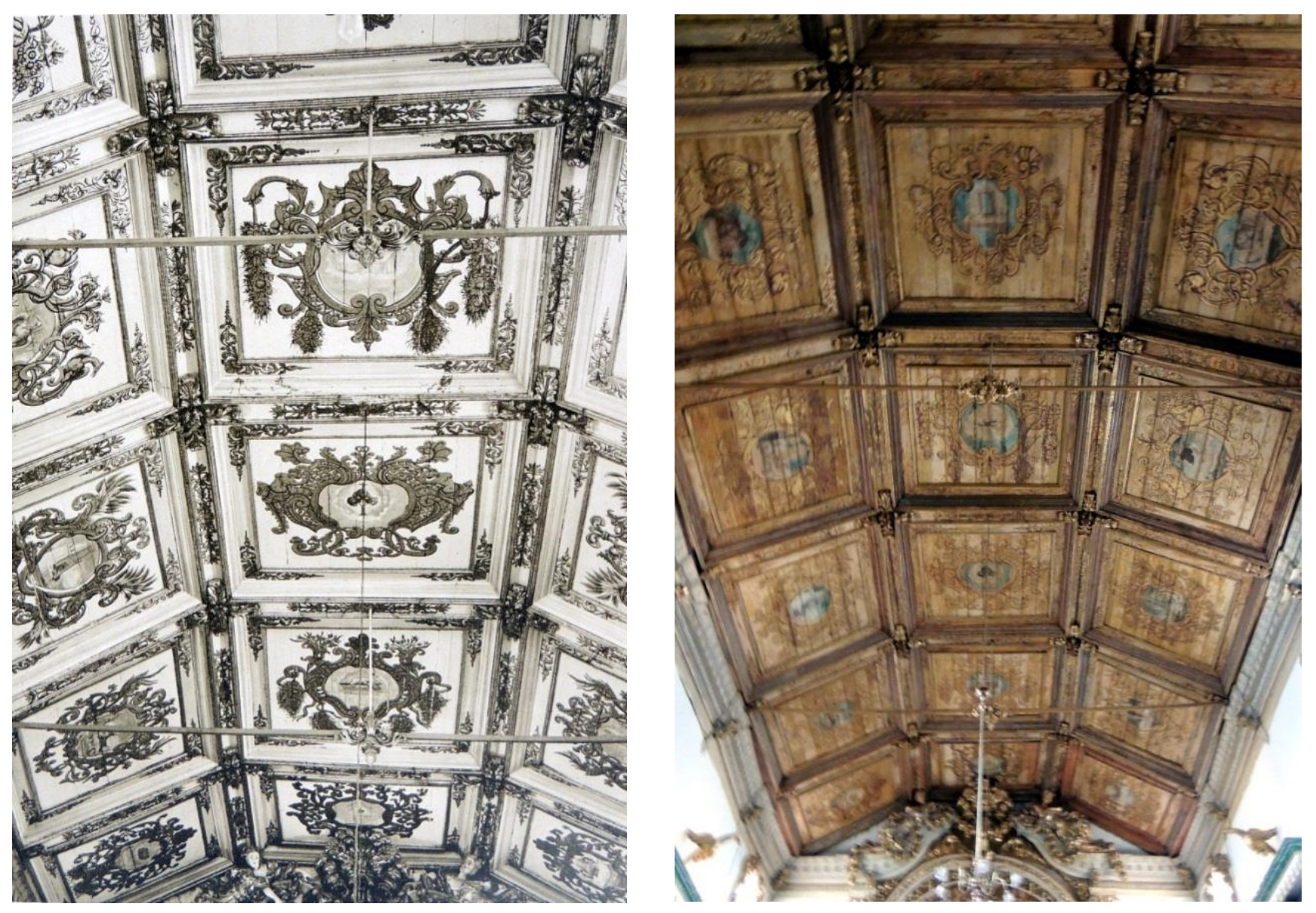

[Figura 07 e 08] Teto da nave Matriz de Santo Antônio antes da intervenção de restauro, década de 1940,

Relíquias da Terra do Ouro e fotografia atual do autor, 2019.

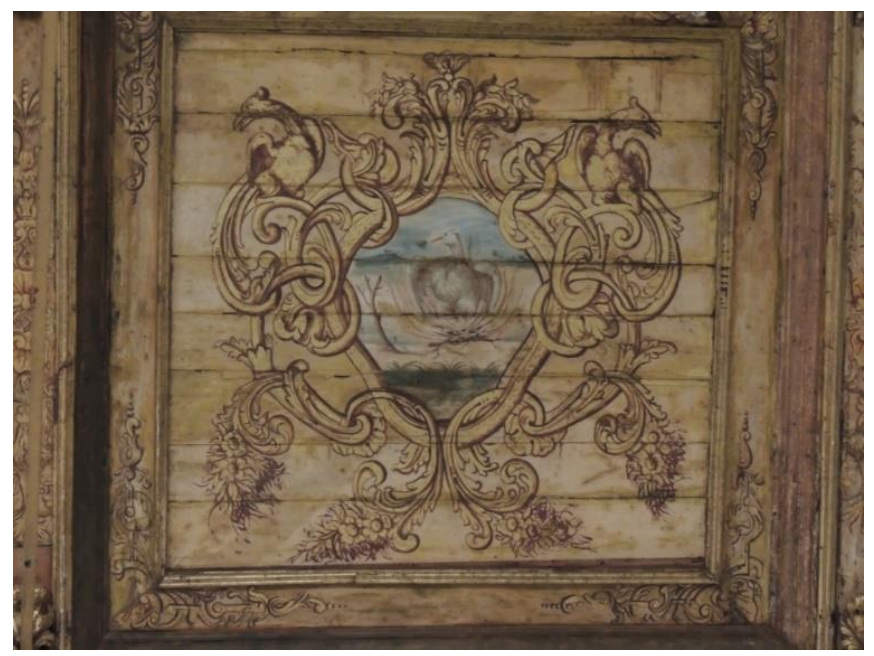

[Figura 09] Detalhe de caixotão do teto da nave Matriz de Santo Antônio.

Fotografia do autor, 2019.

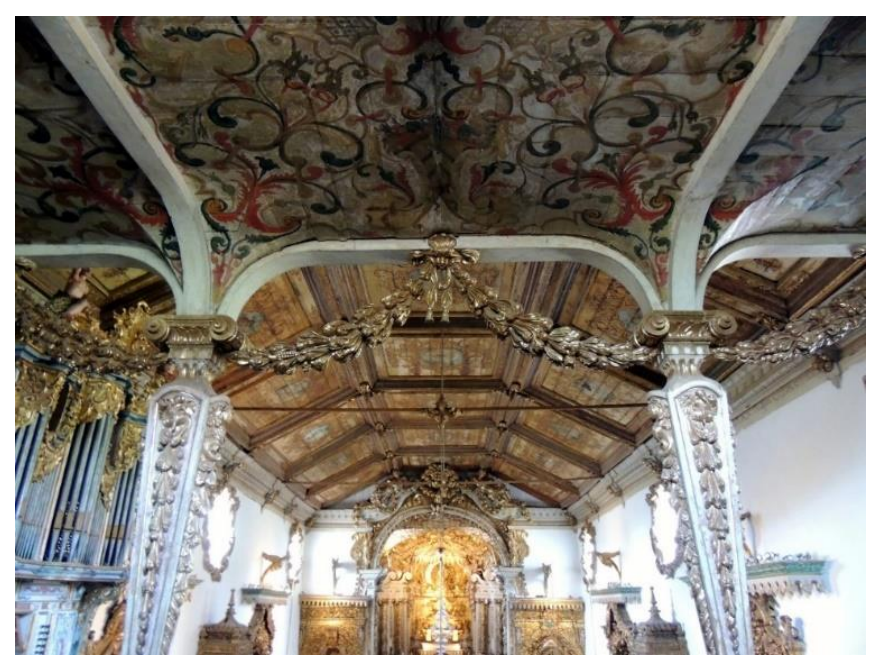

[Figura 10] Detalhe do coro da Matriz de Santo Antônio. Fotografia do autor, 2019. 


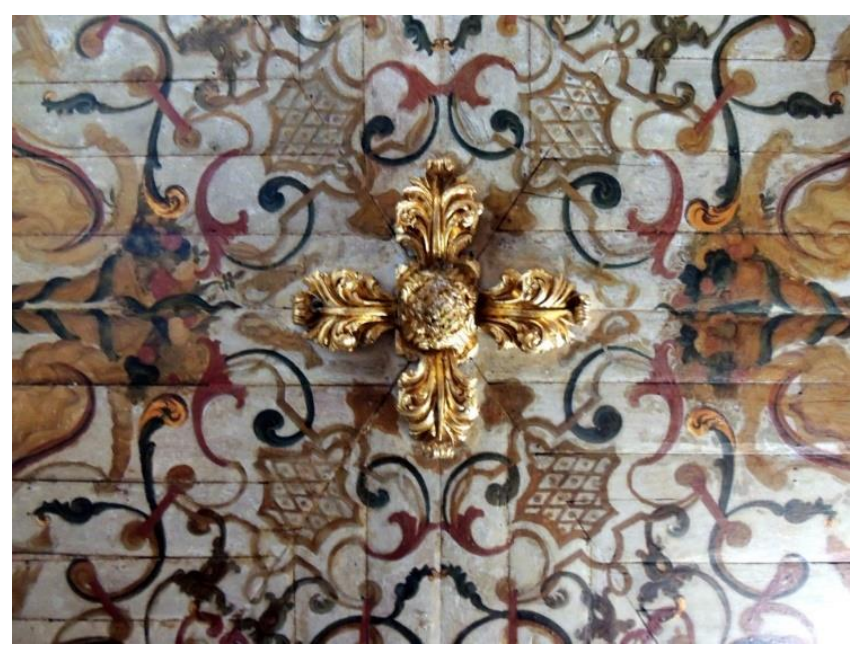

[Figura 11] Detalhe da pintura do teto do coro da Matriz de Santo Antônio, autoria de António Caldas, século XVIII. Fotografia do autor, 2019.

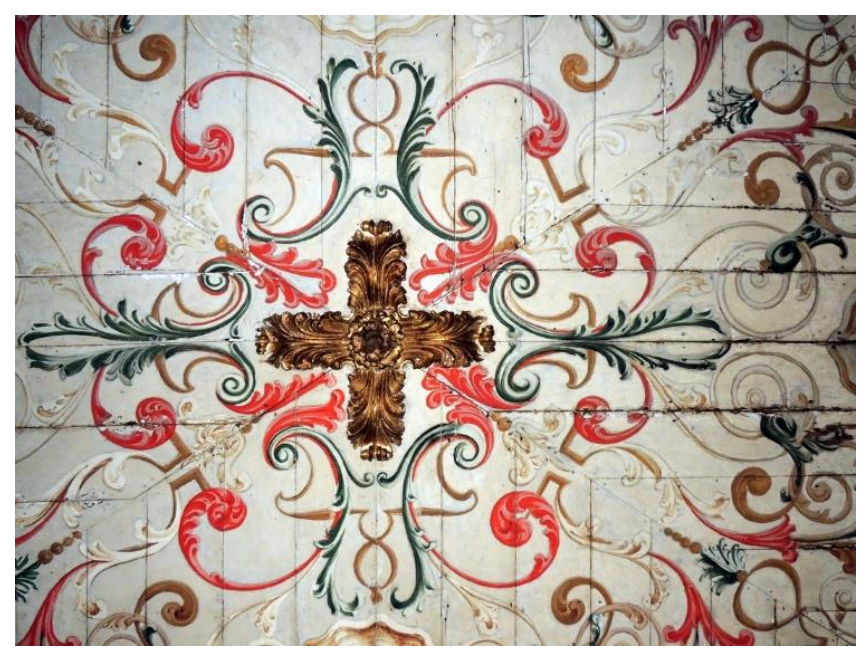

[Figura 12] Detalhe da pintura do teto do nártex da Matriz de Santo Antônio, autoria de António Caldas, século XVIII. Fotografia do autor, 2019.

entalhada, um tipo de baixo-relevo. As mesas dos altares laterais e a cimalha da nave receberam marmorizados, pinturas de fingimento em tom azul da Prússia para as mesas e cinza para a cimalha.

Pelas soluções pictóricas e vocabulário de elementos utilizados na pintura, além do domínio da técnica, não resta dúvida de que todo conjunto é de um único autor - António Caldas.

Em 1787, a Irmandade do Santíssimo Sacramento com o apoio das demais irmandades instaladas na Matriz de Santo Antônio, de Tiradentes, encomendaram um novo órgão ao organeiro portuense Simão Fernandes Coutinho. O instrumento com 630 tubos teve sua caixa entalhada por Salvador de Oliveira e sua decoração pictórica, carnação e douramentos feitos pelo alferes e professor de pintura Manoel Victor de Jesus ${ }^{14}$ (1760?-1828). O coro com decoração barroca recebeu ao final da centúria o instrumento com ornamentação no estilo Rococó. Pintado em tom claro e com motivos rocaille. As rocalhas são bem delineadas nos tons predominantes de azul evermelho, em determinados pontos pequenos buques de flores. Na mísula, desenvolveu-se trama colorida com entalhes nas quinas; na face frontal há a cena de Saul com a lança, ao tentar atingir Davi com a harpa. Nas laterais encontram-se singelas paisagens. Na parte superior, entablamentos de fingimentos, muitas rocalhas e ramos floridos entalhados e dourados. Encimando tudo, um par de anjos trombeteiros. Curiosamente, o pintor registrou a data em que fora executada a pintura: 1798. (fig.13 e14)

A decoração rococó - pictórica e escultórica - do órgão contrasta com a decoração barroca, tanto do coro quanto da nave e da capela-mor.

\footnotetext{
${ }^{14}$ Livro de Receita e Despesa 1761-1797, fls. 135 Vº q se pg a $M^{\text {el }}$ Victor de Jesus d'dourar e pintar o órgão d'Matriz e d'mais q. consta no seu recibo a fls. 108.
} 
Os tetos dialogam estreitamente com os demais elementos que compõem a decoração interna da edificação, especialmente a capela-mor, reconhecida por seu primor. Ainda, há que se destacar que alguns motivos entalhados são repetidos nas pinturas, como as carraras, com soluções muito parecidas, atestando que o conjunto fora idealizado e executado quase simultaneamente. Mas por que se utilizou esse tipo de pintura, sendo que já havia uma nova solução introduzida em Lisboa por Vincenzo Baccharelli, em 1710? Por sua vez, já presente em Salvador, com as obras de António Simões Ribeiro ${ }^{15}$ ? Até em Minas, naquele período, já se experimentava capelas-mores com tetos pintados com quadraturas, com o da Matriz de Nossa Senhora de Nazaré, de Cachoeira do Campo, de autoria de António Rodrigues Bello ${ }^{16}$ e o da Capela de Nossa Senhora do Rosário do Padre Faria, de autoria ignorada, ambas em Vila Rica, atual Ouro Preto? No período em que a pintura da Matriz de Santo Antônio fora executada, o brutesco estava já bem superado e a pintura de arquitetura de fingimento atingira o seu ápice em todo território português.

Teria sido uma opção, um gosto da comitente ou mesmo o universo pictórico que o pintor trouxe consigo em sua memória? Ou ainda, a influência dealgum tratado de brutesco, ou gravura avulsa que tenha circulado pela região? Aspectos difíceis de se obteruma resposta exata.

Asolução pictórica dos tetos da capela-mor, nave, coro e nártex da Matriz de Santo Antônio de Tiradentes seria o grotesco/brutesco ou arabesco? O primeiro pesquisador a tratar com mais atenção essas pinturas foi o professor e pesquisador português Vitor Serrão, em seu artigo A Pintura de Brutesco do Século XVII em Portugal e as suas Repercussões no Brasil, onde ressalta, especialmente sobre o teto da capela-mor dessa matriz:

Esta soberba decoração, de que José Meco nos deu conhecimento em primeira mão, é um explícito testemunho do grau de especialidade atingido pelos artistas radicados em Minas no desenvolvimento pictórico. Composição a têmpera eoiro, num jogo complexo de "ferroneries" ede folhagem acântica [...] integra-se com peculiar felicidade no programa de talha lavrada joanina que forra a ábside, com pleno sentido dinamizador dos espaços. A complexidade composicional avoluma a turgidez das formas entalhadas contribuindo para sublinharo conceito barroco daigreja forradaa oiro, oua "antecâmara do céu", neste caso de Tiradentes particularmente feliz quanto à eficiência dos resultados. [...] No seu conjunto, a lgreja Matriz de Tiradentes constitui um dos mais explícitos exemplos, existentes no mundo português, de integração do brutesco num espaço dinamizado com intervenções múltiplas, seguindo um homogéneo programa de formas e deslumbramentos barrocos. ${ }^{17}$

Serrão enfatiza a integração entre a talha joanina e a pintura de brutescos na Matriz de Santo Antônio de Tiradentes, mas destaca ainda que essa solução pictórica já era arcaizante para o período em que fora executada, pois os tetos pintados com quadraturasjá estavam em execuçãoem edificações mineiras. Caso bastante curioso o da Matriz

\footnotetext{
${ }^{15}$ O quadraturista António Simões Ribeiro deixou Lisboa para se radicar em Salvador em 19 de janeiro de 1735, conforme SERRÃO, Vitor. A Pintura Proto-Barroca em Portugal (1640-1706) e o seu Impacto no Brasil. Belo Horizonte: Revista Barroco, No 18 , anos 1997/2000, p. 269-291.

${ }^{16}$ BOHRER, Alex. Os Diálogos de Fênix - Fontes Iconográficas, Mecenato e Circularidade no Barroco Mineiro. Dissertação de Mestrado apresentado ao Departamento de Pós-Graduação em História da Faculdade de Filosofia e Ciências Humanas da Universidade Federal de Minas

Gerais. Belo Horizonte: UFMG, 2007, p. 66.

${ }^{17}$ SERRÃO, Vitor. A Pintura de Brutesco do Século XVII em Portugal e as suas Repercussões no Brasil. Belo Horizonte: Revista Barroco, $N^{\circ} 15$, anos 1990/2, p. 113-136.
} 
de Nossa Senhora de Nazaré, de Cachoeira do Campo, que teve sua capela-mor pintada com uma quadratura e na nave caixotões com motivos de brutescos e cenas pagãs. Também as monumentais pinturas da capela-mor da Matriz de Nossa Senhora da Conceição, de Conceição do Mato Dentro, especialmente as arquitetônicas das ilhargas. Pode ter sido uma opção da comitente ou uma proposta do próprio autor. Ainda nesse trabalho, Serrão apresentou uma série de tetos pintados com motivos brutescados - obras datadas ou documentadas de 1625 a 1725, realizadas em regiões diversas de Portugal, onde há mais de duas centenas de obras nesse estilo, mas listou 92 delas, sendo que 21 desapareceram, por vários motivos, inclusive o terremoto ocorrido em Lisboa em 1755, quando algumas edificações ruíram e outras foram destruídas por incêndios. Alguns desapareceram pela substituição e renovação do gosto. No Brasil, especialmente na Região Sudeste e Nordeste, há diversos tetos pintados com o motivo brutesco, mas não há inventário para que se possa ter ideia aproximada de quantos são. Tetos brutescados em caixotão de exímia qualidade encontram-se na Sé de Salvador-BA, na Capela de Nossa Senhora do Ó, de Sabará-MG e na Matriz de Nossa Senhora de Nazaré, de Cachoeira do Campo, Ouro Preto-MG. (fig.15-19)

O conceito de grottesche vem da grotte neroniana, apropriado pelo Maneirismo de extravagância e de ambuiguidade. A partir do Renascimento, quando se localizou a Domus Aurea, cerca de 1480, a casa do imperador Nero, em Roma, muitos que a visitaram ficaram impressionados com as pinturas que ornavam a grotte, ou gruta, que passaram a influenciar a nova produção decorativa e pictórica italiana. Logo, as ideias dessa pintura começaram a circular e chegaram a Portugal, através das gravuras avulsas e também de tratados, como os de Claude Audran (1658-1734) e Jean Bérain (1640-1711) e outros.

O conceito de grottesche vem da grotte neroniana, apropriado pelo Maneirismo de extravagância e de ambuiguidade. A partir do Renascimento, quando se localizou a Domus Aurea, cerca de 1480, a casa do imperador Nero, em Roma, muitos que a visitaram ficaram impressionados com as pinturas que ornavam a grotte, ou gruta, que passaram a influenciar a nova produção decorativa e pictórica italiana. Logo, as ideias dessa pintura começaram a circular e chegaram a Portugal, através das gravuras avulsas e também de tratados, como os de Claude Audran (16581734) e Jean Bérain (1640-1711) e outros.

Segundo Serrão, em Portugal, de maneira sumária, as tipologias do brutesco podem ser:

$1^{0}$ período - arcaizante: ainda inserido dentro da tradição maneirista, em que a influência da "ferroneries" flamengas se associa a um imaginário decorativo variado [...].

$\mathbf{2}^{\circ}$ período-de nacionalização do brutesco, ou de plena autonomia triunfante do gênero, em que as soluções barrocas se refinam em robustez e simplificação de "motivos" - com refinamento e maior elegância dos enrolamentos acânticos e profusão de elementos "gordos"-, que corresponde aos anos de estabilidade do reinado de D. Pedro II [...]

$3^{0}$ período - de convergência com a "perspectiva ilusionista", momento de declínio do brutesco como gênero pictórico autónomo, quando a introdução do gosto pelas decorações perspectivadas 
de arquitetura fingida, espetacularmente experimentada pelo pintor italiano Vincenzo Baccarelli no tecto da Portaria de S. Vicente de Fora (1710) $[. . .]^{18}$

OpesquisadorSerrão, um dos maiores estudiosos dos tetos pintados com o motivo brutesco, definiraa pintura da capela-mor de Tiradentes sendo do tipo ferroneries ${ }^{19}$, como as executadas em tetos portugueses do século XVII, mas pouco mais adiante referiu-se a ela como "a majestosa intervenção brutescada da cobertura, verdadeiramente um dos documentos em que o brutesco nacional atingiu uma linguagem mais exuberante e integradora!" Seria esta pintura do segundo período, a transição entre os estilos Maneirista e o Barroco?

Magno Moraes Mello, em sua obra A Pintura de Tectos em Perspectiva no Portugal de D. João V ${ }^{20}$, resultado de sua tese de Mestrado, apresentada no Departamento de História da Arte da Universidade de Lisboa, com prefácio do professor e pesquisador Vitor Serrão, também investigou profundamente a produção de tetos pintados com motivos brutescados em regiões diversas de Portugal. Embora o enfoque de seu trabalho seja as quadraturas, seria impossível estudá-las, antes de analisar seus antecedentes portugueses, os brutescos, que tão bem foram apropriados, desenvolvidos nas terras lusitanas e levados para longínquos territórios coloniais, como o Brasil. Nessa obra, Magno Mello apresentou mais uma tipologia:

[...] éjá definido como brutesco nacional, utilizado entre o reinado de D. Pedro ll até o reinado de D. João $V$, desde as decorações maneiristas até a fase barroca, constituindo uma quarta tipologia. Em linhas gerais, esta fase caracteriza-se pelo desaparecimento das figuras pagãs, pelo recurso a soluções mais robustas e pelo maior volume das flores. ${ }^{21}$

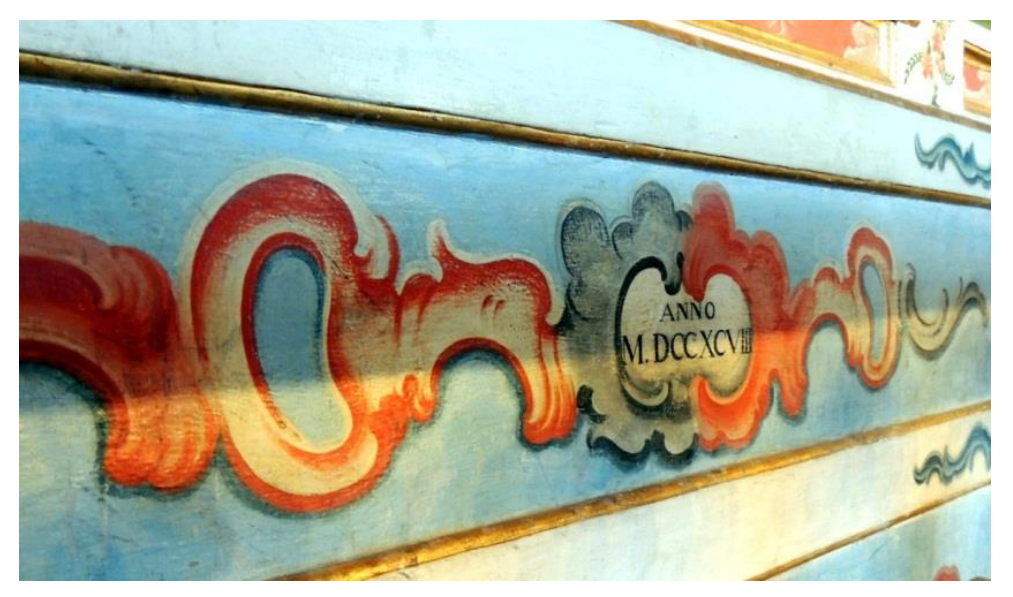

\section{[Figura 13]}

Aspecto da decoração pictórica do órgão da Matriz de Santo Antônio, autoria de Manoel Victor de Jesus, século XVIII.

Fotografia do autor, 2019.

\footnotetext{
${ }^{18}$ SERRÃO, Vitor. Op. Cit., 1990-92, p. 118-19.

${ }^{19}$ As ferroneries que circularam em Portugal e inspiraram os pintores foram versões de gravuras ítalo-flamengas, impressas em Antuérpia.

${ }^{20}$ MELLO, Magno Moraes. A Pintura de Tectos em Perspectiva no Portugal de D. João. Lisboa: Editora Estampa, 1998.

${ }^{21}$ MELLO, Magno Moraes. Op. Cit., 1998, p. 31.
} 

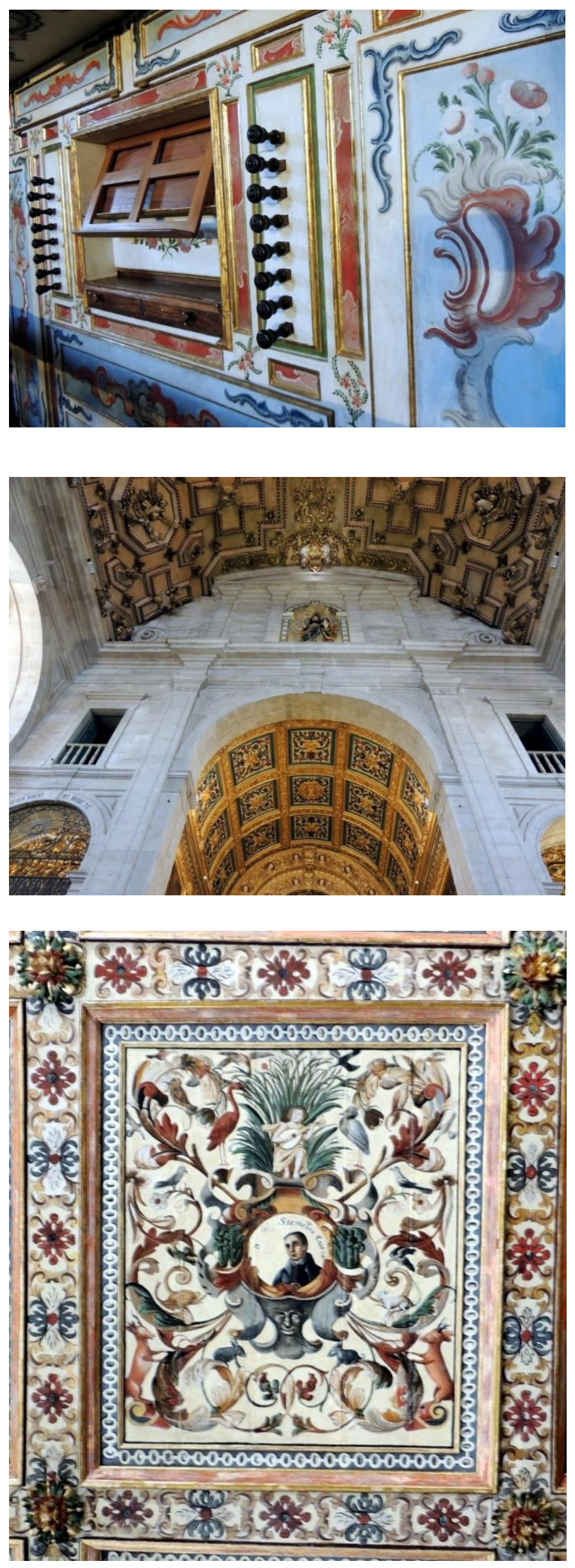

[Figura 14] Aspecto da decoração pictórica do órgão da Matriz de Santo Antônio, autoria de Manoel Victor de Jesus. Fotografia do autor, 2019.

\section{[Figura 15]}

Teto em caixotão da capela-mor da Sé de Salvador. Fotografia do autor, 2019.

\section{[Figura 16]}

Caixotão da sacristia da Sé de Salvador, brutesco com elementos fitomórficos, zoomórficos e antropomórficos.

Fotografia do autor, 2019. 
No conjunto de tetos da Matriz de Tiradentes há a presença de ferroneries na capela-mor e nos caixotões com cartelas brutescadas, não apresentam figuras pagãs. Enquanto que na Matriz de Nossa Senhora de Nazaré de Cachoeira do Campo, em Ouro Preto, no teto de caixotão da nave há a presença de figuras mitológicas, um dos indicadores de que essa obra pode ser anterior a de Tiradentes, provavelmente da década de 1720.

Em Florencia y Bagdad - Una historia de la mirada entre Oriente y Occidente ${ }^{22}$, de Hans Belting, o autor apresenta amplo e profundo estudo histórico sobre a óptica, a imagem e o olhar. Contempla ainda a geometria e as artes decorativas - 0 arabesco. A própria palavra já indica a origem desse elemento ornamental que fora amplamente utilizado na decoração de utensílios domésticos enobrecidos com pinturas geométricas ou vegetais, muito utilizado como moda oriental. O autor apresentou a imagem "Troféus e arabescos" e analisou como a imagem deveria ser vista. Trata-se de uma gravura, um círculo tendo a metade imagens sombreadas e com profundidade e ao centro o retrato do retrato do imperador Caesar. A outra metade é um desenho linear, uma simetria horizontal, denominado arabesco, espelhado em eixo, que ocupou toda área do círculo. O arabesco fora muito apreciado, especialmente em Veneza e Gênova. Belting salienta que há vasta literatura sobre o tema, que teve desenvolvimento a partir do século XIII. Plantas e rolos foram se transformando também em formas geométricas. Mas foi no século XVI que o arabesco teve ampla difusão por toda Itália, através da circulação das imagens.

A cultura árabe fora difundida na Europa, principalmente na Península Ibérica ao longo da ocupação que durou toda a Idade Média e só terminou no início da Idade Moderna, quando finalmente foram expulsos pelos reis Fernando e Isabel. Portugal absorveu muitas influências, nas artes, na arquitetura, nos costumes e até mesmo na língua portuguesa que incorporou cerca de 700 palavras de origem árabe. Em terras lusíadas, 0 arabesco foi muito bem aceito. Portanto, arabesco e brutesco se fundem. (fig.20)

Entre o brutesco e o arabesco, considerando as apreciações dos pesquisadores, Vitor Serrão, Magno Mello e de Hans Belting diante o conjunto de tetos pintados da Matriz de Santo Antônio, podemos considerar que os tetos da capela-mor, nave e coro são de motivos do brutesco, enquanto o do teto do nártex pode ser o arabesco, por ser constituído apenas por formas fitomórficas coloridas sobre o fundo branco, plenamente desprovida de sombreado ou profundidade. (fig.21)

\section{Considerações Finais}

A exuberância da talha joanina da Matriz de Santo Antônio de Tiradentes, amplamente reconhecida como uma das mais primorosas do universo luso-brasileiro, dialoga estreitamente com o conjunto de tetos pintados e os demais elementos pictóricos. Muito além de preencher espaços, as ferroneries, os brutescos e os

\footnotetext{
${ }^{22}$ BELTING, Hans. Florencia y Bagdad - Uma historia de la Mirada entre Oriente y Occidente. Madrid: Akai, 2008.
} 


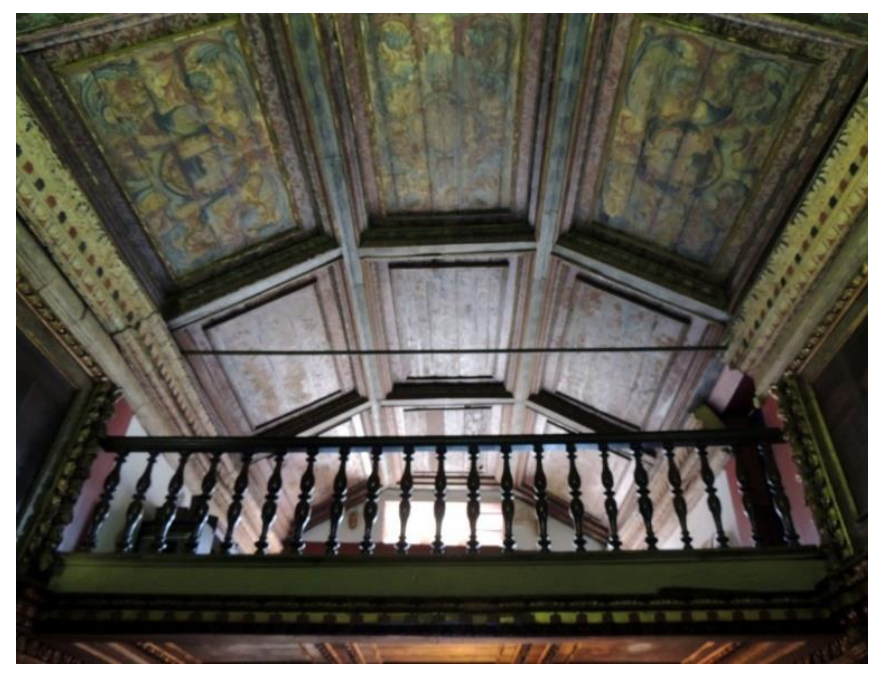

[Figura 17] Aspecto do teto em caixotão da nave da Capela de Nossa Senhora do Ó, Sabará-MG. Fotografia do autor, 2018.

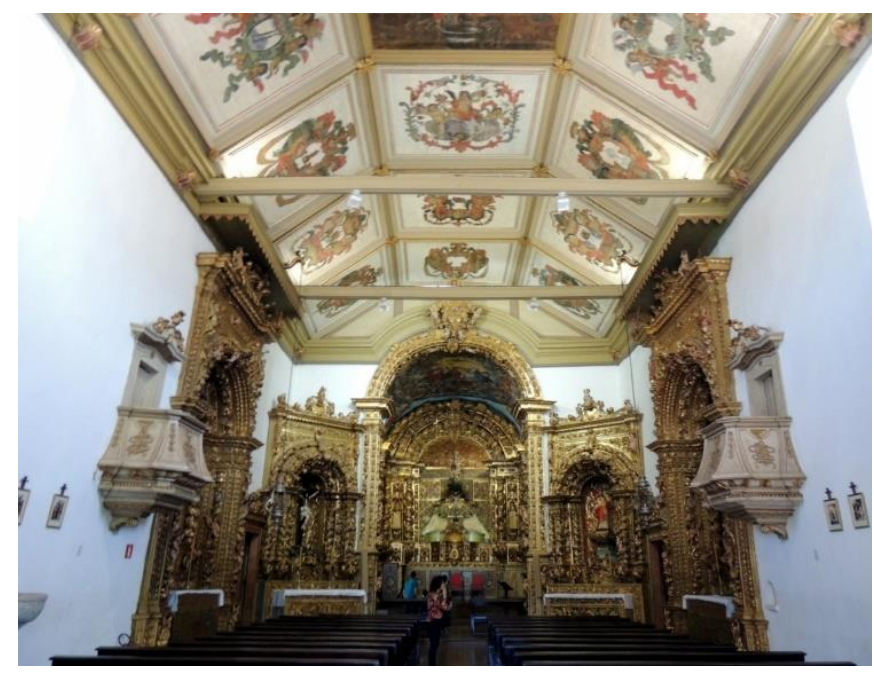

[Figura 18] Aspecto do teto em caixotão da nave da Matriz de Nossa Senhora de Nazaré, trifacetado, Cachoeira do Campo, Ouro Preto-MG. Fotografia do autor, 2019.

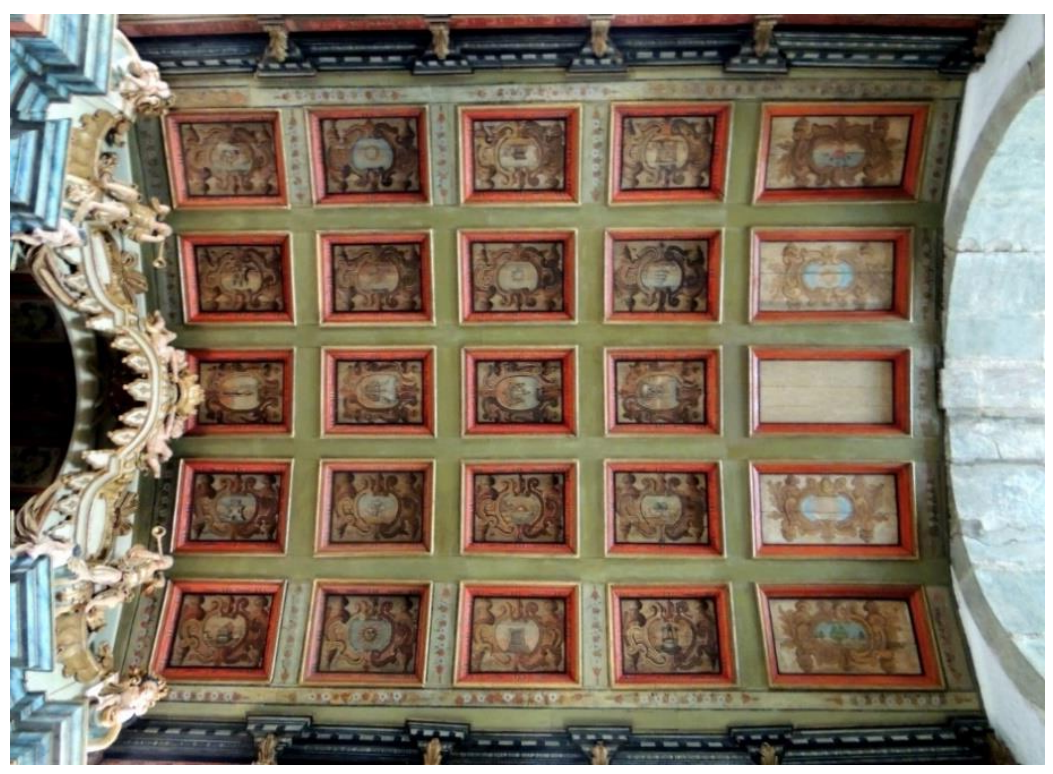

[Figura 19] Teto da Capela de Nossa Senhora da Ajuda, caixotão pentafaceado, um dos raros em Minas Cerais, Alto Maranhão, Congonhas-MC. Fotografia do autor, 2019.

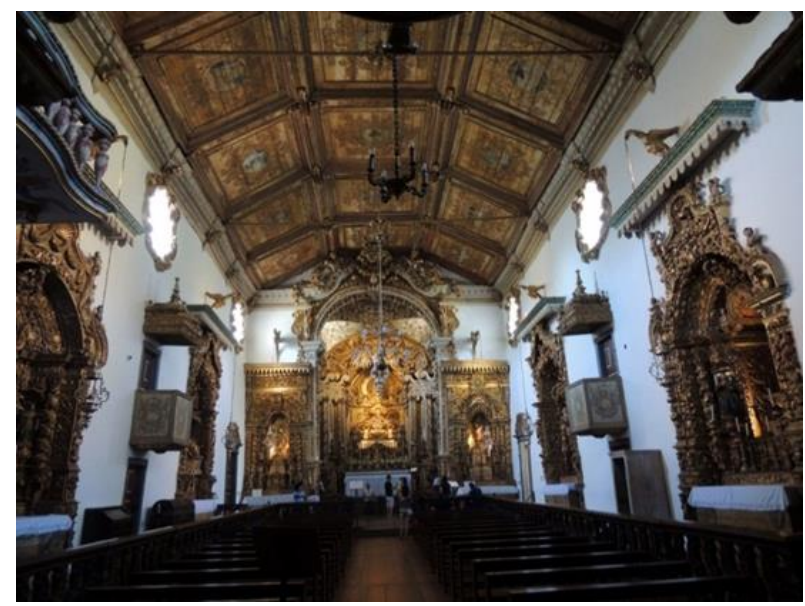

[Figura 21] Nave e capela-mor da Matriz de Santo Antônio. Fotografia do autor, 2019.

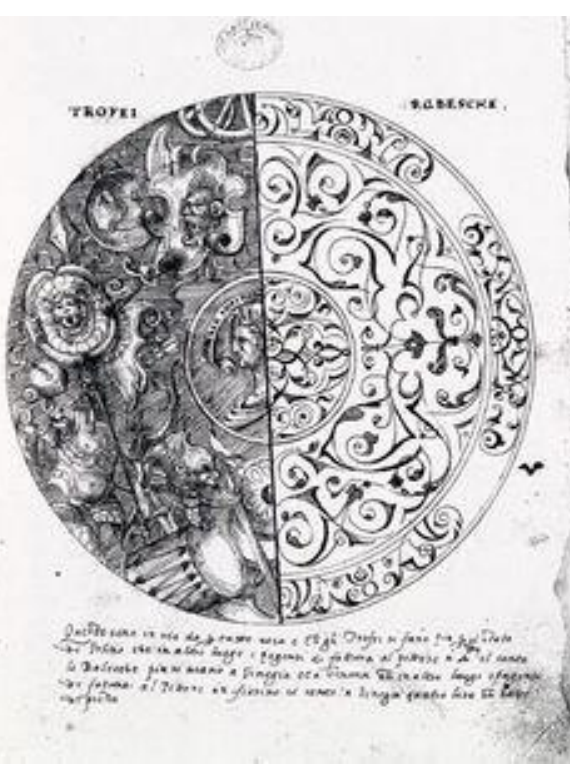

[Figura 20] Tratado de arte e cerâmica, de Cipriano Piccolpasso, Arte do Oleiro, 1559: Troféus e arabescos. Arquivo do autor. 
arabescos valorizam a talha joanina. Especialmente a capela-mor, toda dourada, que funciona realmente como uma "antecâmara do céu", impacta o fiel, o observador e o contemplador. Com tanta profusão de detalhes - da talha, das pinturas, das esculturas, da iluminação que penetra pelos ocúlos salientando os claros e escuros, permite visualizar mais adequadamente as soluções plásticas adotadas, com significativo domínio. Mas para compreender e apreciar tantos detalhes é necessário um olhar atento.

Toda decoração interna dessa edificação só foi possível graças a circularidade, não apenas de artistas pintores, entalhadores e escultores, também de gravuras, tratados, obras de arte, materiais pictóricos, bíblias ilustradas, livros de arte, até de retábulos inteiros, mas principalmente do trânsito de ideias. Do Brasil partiram os lingotes de ouro, preparados nas Casas de Fundição, onde já se descontava o quinto destinado à Coroa Portuguesa. Depois, o mesmo ouro retornava à colônia, adquirido pelas irmandades mineiras, as comitentes das obras de igrejas e capelas, que compravam os livros de folhas batidas de ouro e prata. No Brasil não havia mestre batefolha, então se importava as folhas para o acabamento do interior dos templos. Com ouro, muito ouro, e diversas soluções artísticas a Matriz de Santo Antônio recebeu decoração soberba, uma das mais exuberantes do barroco luso-brasileiro, fruto de ampla circulação.

A decoração do corpo principal da Matriz de Santo Antônio de Tiradentes é barroca, predominantemente, mas é também maneirista e rococó.

\section{Referências bibliográficas}

BAZIN, Germain. A arquitetura religiosa Barroca no Brasil - Estudo histórico e morfológico. Rio de Janeiro: Editora Record, s.d..

BELTING, Hans. Florencia y Bagdad -Uma historia de la Mirada entre Oriente y Occidente. Madrid: Akai, 2008. BOHRER, Alex. Os Diálogos de Fênix-Fontes Iconográficas, Mecenatoe Circularidade no Barroco Mineiro. Dissertação de Mestrado apresentado ao Departamento de Pós-Graduação em História da Faculdade de Filosofia e Ciências Humanas da Universidade Federal de Minas Cerais. Belo Horizonte: UFMG, 2007, [mímeo].

CRUZ, Luiz Antonio da. e BOAVENTURA, Maria José. Clossário do Patrimônio de Tiradentes-MG. Tiradentes: IHCT, 2015. FALCÃO, Edgard de Cerqueira. Relíquias da Terra do Ouro. São Paulo: Graphicars-F.Lanzara, 1946.

LEVY, Levy. Modelos europeus na pintura colonial. Rio de Janeiro: Revista do SPHAN, Rio de Janeiro: 1944, vol. 8, p. 7-66. MARTINS, Judith. Dicionário de Artistas e Artífices dos Séculos XVIII e XIX em Minas Gerais. Rio de Janeiro: Publicações do Instituto do Patrimônio Histórico e Artístico Nacional, Nº 27, 1974, primeiro volume.

MELLO, Magno Moraes. A Pintura de Tectos em Perspectiva no Portugal de D. João. Lisboa: Editora Estampa, 1998. OLIVEIRA, Eduardo Pires de. Minho e Minas Gerais no século XVIII. Braga: Edição do autor, 2016.

PEDROSA, Aziz José de Oliveira. A produção da talha joanina na Capitania de Minas Gerais - retábulos, entalhadores e oficinas. Belo Horizonte: Incipit, 2019.

SERRÃO, Vitor. A Pintura de Brutesco do Século XVII em Portugal e as suas Repercussões no Brasil. Belo Horizonte: Revista Barroco, Nº 15, anos 1990/2, p. 113-136.

SERRÃO, Vitor. A Pintura Proto-Barroca em Portugal (1640-1706) e o seu Impacto no Brasil. Belo Horizonte: Revista Barroco, No ${ }^{\circ}$, anos 1997/2000. 